\title{
Managing Polypharmacy in Older Adults with Cancer Across Different Healthcare Settings
}

\author{
Andrew Whitman (D) \\ Paige Erdeljac ${ }^{2}$ \\ Caroline Jones' \\ Nicole Pillarella $\mathbb{1}^{3}$ \\ Ginah Nightingale ${ }^{3}$ \\ 'Department of Pharmacy, University of \\ Virginia Health, Charlottesville, VA, USA; \\ ${ }^{2}$ Department of Pharmacy, James Cancer \\ Hospital and Solove Research Institute, \\ Columbus, OH, USA; ${ }^{3}$ Department of \\ Pharmacy Practice, Jefferson College of \\ Pharmacy, Thomas Jefferson University, \\ Philadelphia, PA, USA
}

Correspondence: Ginah Nightingale Jefferson College of Pharmacy, Thomas Jefferson University, Department of Pharmacy Practice, 90I Walnut Street Suite 946, Philadelphia, PA, 19107, USA

Tel + $1215-503-3794$

$\mathrm{Fax}+1215-503-9052$

Email ginah.nightingale@jefferson.edu

\begin{abstract}
The care of older patients with cancer is becoming increasingly complex. Common challenges for this population include management of comorbidities, safe transitions of care, and appropriate medication use. In particular, polypharmacy-generally defined as the regular use of five or more medications - and inappropriate medication use can lead to adverse effects and poor outcomes in older adults with cancer, including falls, hospital readmissions, cognitive impairment, poor adherence to essential medications, chemotherapy toxicity, and increased mortality. Managing polypharmacy across different cancer care settings is often challenging. Providers face barriers to safe and successful medication management that may include lack of time, absence of reimbursement, underappreciation of the scale of polypharmacy-related harm, lack of ownership of deprescribing efforts, and poor communication across care settings. Existing literature on managing inappropriate medication use and polypharmacy in older adults with cancer has often focused on ideal state settings in which resources are plentiful and time is purposefully allocated for medication interventions. This paper presents a narrative, rather than a systematic review, of studies published in the past decade that provided detailed information on medication management and polypharmacy across cancer care settings. This review aims to also summarize different healthcare provider roles in taking action against inappropriate medication use and polypharmacy in older adults with cancer.
\end{abstract}

Keywords: geriatric oncology, polypharmacy, potentially inappropriate medication, medication management, deprescribing, cancer care setting, interprofessional team

\section{Introduction}

The care of older patients with cancer is becoming increasingly complex. This complexity may comprise management of comorbidities, safe transitions of care, and appropriate medication use. In particular, polypharmacy—generally defined as the regular use of five or more medications - and inappropriate medication use can lead to adverse effects and poor outcomes in older adults with cancer, including falls, hospital readmissions, cognitive impairment, poor adherence to essential medications, chemotherapy toxicity, and increased mortality. ${ }^{1}$

Healthcare experts have noted that addressing such medication use represents an important opportunity to improve medical care for older adults. ${ }^{2}$ However, managing polypharmacy across different cancer care settings is often challenging. Barriers for providers to safely and successfully manage medications include lack of time, absence of reimbursement, underappreciation of the scale of polypharmacy-related harm, lack of ownership of deprescribing efforts, and poor communication across care settings. ${ }^{3,4}$ Many of these challenges can be abated by the 
introduction of clinical pharmacy services, with several studies showing positive benefits when pharmacists are added to the care team for older adults with cancer. ${ }^{5,6}$

Existing literature on managing inappropriate medication use and polypharmacy in older adults with cancer has often focused on ideal state settings in which resources are plentiful and time is purposefully allocated for medication interventions. In real life, this ideal state is often not feasible in different cancer care settings. For instance, while larger academic medical centers may have multiple dedicated pharmacists to conduct medication reviews, small hospitals may not. Thus, our paper presents a narrative, rather than a systematic review, of studies published in the past decade that provided detailed information on medication management and polypharmacy across cancer care settings. These studies included cohorts of patients diagnosed with solid tumor malignancies, hematologic malignancies and surgical oncology patients.

With our narrative review, we aim to summarize different healthcare provider roles in taking action against inappropriate medication use and polypharmacy in older adults with cancer (Box 1 describes how to use this review). It is the first review of its kind to summarize potential clinician roles in evaluating polypharmacy in various cancer care settings. Each section describes nuances and differences in priorities within each care setting aimed at combating polypharmacy in older adults with cancer as detailed in Table 1. Along with noting differences in care setting priorities, this paper emphasizes the importance of examining individual patient context when making medication-related decisions. For older adults with cancer, geriatric syndromes (eg, falls, frailty, cognitive impairment, mobility issues) and the issue of chronologic age versus functional age can be directly aligned with polypharmacy assessments and deprescribing decisions. Todd et $\mathrm{al}^{7}$ recently explored patient context as it relates to deprescribing recommendations and developed a conceptual framework called "the deprescribing rainbow" that considers clinical, psychological, social, financial, and physical determinants for assisting with deprescribing decisions. The global themes of the deprescribing rainbow framework highlight the heterogeneity of the older adult population and acknowledge the evolving care needs of the individual patient; these themes are consistent with the established role of person-centered care in managing medications in older adults with cancer. ${ }^{7}$

\section{Box I How to Use This Review}

- Review the entirety of this paper or jump to the applicable section according to individual discipline or work setting (eg, a nurse practicing in outpatient clinics may obtain the most benefit from the text and corresponding tables in the "ambulatory setting" section).

- Each row within the table outlines the various roles of clinicians in different care settings and indicates where overlap of practice and concepts exist.

- Consider the bottom line recommendation box a "call to action" on what the authors consider the most evidence-based area or idea worth exploring in future research on polypharmacy in older adults with cancer.

- Clinicians are encouraged to make simple changes and adopt what makes sense for their practice site. Applying all recommendations in a specific care setting may not be feasible initially.

Finally, this review attempts to identify gaps in knowledge and lay out areas of interest for future research efforts. It should be noted that even within seemingly identical care settings, there may be unique challenges that prevent optimal services. One example is use of screening tools to identify polypharmacy and potential inappropriate medication (PIM) use. While screening tools are not required for identifying polypharmacy and PIMs, they can certainly streamline the process. For some clinicians, awareness and implementation of a screening tool may not be a part of their routine workflow while caring for older adults with cancer. It is also important to note that not all screening tools are specific to older adults with cancer, and some tools are more user friendly than others. Existing data support the application of three medication screening tools for older adults with cancer: Beers Criteria, Medication Appropriateness Index (MAI), and the Screening Tool of Older Persons' Prescriptions (STOPP). Beers Criteria and STOPP are both explicit screening tools that help clinicians quickly screen for inappropriate therapies based on potential medication-induced harm or diseasemedication discrepancies. The MAI is an implicit scoring-based tool that helps determine appropriateness based on a defined set of criteria (eg, indication, efficacy, dosage, directions, cost, drug-drug interactions, drugdisease interactions, and medication duplication); each medication screened with the MAI is subsequently deemed to be inappropriate, marginally appropriate, or appropriate. An extensive review of screening tools for PIMs and polypharmacy in the context of geriatric oncology is beyond the scope of this review but has been described elsewhere. ${ }^{3,8}$ 
Table I Healthcare Provider Tasks Associated with Managing Polypharmacy in Older Adults with Cancer Across Different Healthcare Settings

\begin{tabular}{|c|c|c|c|c|}
\hline $\begin{array}{l}\text { Practice } \\
\text { Setting }\end{array}$ & Pharmacy Tasks & Provider Tasks & Nursing Tasks & $\begin{array}{c}\text { Bottom Line } \\
\text { Recommendation }\end{array}$ \\
\hline $\begin{array}{l}\text { Academic } \\
\text { Medical } \\
\text { Center } \\
\text { Inpatient } \\
\text { Setting }\end{array}$ & $\begin{array}{l}\text { - Flag prescribing inertia at time } \\
\text { of admission to hospital, espe- } \\
\text { cially for patients admitted } \\
\text { through the emergency } \\
\text { department. } \\
\text { - Involve patients and caregivers } \\
\text { in the deprescribing process } \\
\text { (eg, keep patients up-to-date on } \\
\text { any medication changes). } \\
\text { - Promote awareness of depre- } \\
\text { scribing services on the inpati- } \\
\text { ent units (eg, market services to } \\
\text { providers and patients alike). } \\
\text { - Champion the formation of an } \\
\text { Oncology-Acute Care for } \\
\text { Elders unit with a focus on } \\
\text { polypharmacy assessment. }\end{array}$ & $\begin{array}{l}\text { Recognize common instances of } \\
\text { prescribing inertia (eg, if reason } \\
\text { for admission is due to compli- } \\
\text { cations from a fall, medications } \\
\text { should always be considered } \\
\text { a potential contributing factor). } \\
\text { - Promote awareness of depre- } \\
\text { scribing services on the inpati- } \\
\text { ent units (eg, recommend } \\
\text { available pharmacists services to } \\
\text { patients and caregivers). } \\
\text { Work with an interprofessional } \\
\text { team to flag barriers to depre- } \\
\text { scribing (eg, inability to coordi- } \\
\text { nate with outside specialist } \\
\text { physicians). }\end{array}$ & $\begin{array}{l}\text { Promote proactive assess- } \\
\text { ments of potentially inap- } \\
\text { propriate medication therapies } \\
\text { (eg, bring concerns to phar- } \\
\text { macists and providers as soon } \\
\text { as possible). } \\
\text { - Collaborate with pharmacy } \\
\text { staff in potential Oncology- } \\
\text { Acute Care for Elders } \\
\text { rounding. } \\
\text { - Utilize tools to complete } \\
\text { screening for delirium and falls. }\end{array}$ & $\begin{array}{l}\text { - Continuation of inappropriate } \\
\text { therapies is common in the } \\
\text { hospital setting; breaking pre- } \\
\text { scribing inertia can successfully } \\
\text { occur during hospital } \\
\text { admissions. } \\
\text { - Interprofessional team resources } \\
\text { are necessary to manage falls and } \\
\text { delirium related to inappropriate } \\
\text { medication therapies. } \\
\text { Deprescribing is feasible during } \\
\text { a hospital stay; therefore, clini- } \\
\text { cians should promote awareness } \\
\text { of the available service to col- } \\
\text { leagues, patients, and caregivers. }\end{array}$ \\
\hline $\begin{array}{l}\text { Academic } \\
\text { Medical } \\
\text { Center } \\
\text { Ambulatory } \\
\text { Care Setting }\end{array}$ & $\begin{array}{l}\text { Perform comprehensive medica- } \\
\text { tion reconciliation (drug name, } \\
\text { strength, route, frequency, } \\
\text { duration, indication) using the } \\
\text { patient provided list, electronic } \\
\text { medical record, records from } \\
\text { outside pharmacy and claims } \\
\text { data. } \\
\text { Assess medication adherence. }\end{array}$ & $\begin{array}{l}\text { Perform an independent review } \\
\text { of the reconciled medication list } \\
\text { using the patient provided list, } \\
\text { electronic medical record. } \\
\text { Collaborate with an interprofes- } \\
\text { sional team (eg, licensed inde- } \\
\text { pendent practitioners, } \\
\text { pharmacists, nurses, social } \\
\text { work) to optimize medication } \\
\text { use. }\end{array}$ & $\begin{array}{l}\text { Flag patients that may benefit } \\
\text { from a comprehensive medica- } \\
\text { tion review. }\end{array}$ & $\begin{array}{l}\text { - Aim to deter preventable hospi- } \\
\text { talizations and emergency } \\
\text { department visits. } \\
\text { - Develop a process for conduct- } \\
\text { ing periodic comprehensive } \\
\text { medication reviews for patients } \\
\text { in need. } \\
\text { - Evaluate cancer-related medica- } \\
\text { tions and medications for other } \\
\text { comorbid conditions. }\end{array}$ \\
\hline $\begin{array}{l}\text { Surgical } \\
\text { Oncology } \\
\text { Setting }\end{array}$ & $\begin{array}{l}\text { Perform comprehensive medica- } \\
\text { tion review in order to optimize } \\
\text { medication use (eg, assessing } \\
\text { indication, limiting side effects, } \\
\text { limiting drug-drug interactions, } \\
\text { assessing cost, limiting pill } \\
\text { burden). } \\
\text { Assess the need to discontinue } \\
\text { certain high-risk medications } \\
\text { before surgery (eg, fall-inducing } \\
\text { medications, delirium-inducing } \\
\text { medications, medications that } \\
\text { increase bleeding risk). }\end{array}$ & $\begin{array}{l}\text { Ensure that medications have } \\
\text { been reviewed prior to the sur- } \\
\text { gery in order to reduce the risk } \\
\text { of post-surgical adverse events } \\
\text { (eg, falls, delirium). }\end{array}$ & $\begin{array}{l}\text { Promote proactive medication } \\
\text { reviews for patients. } \\
\text { - Work collaboratively with } \\
\text { medication use (eg, communi- } \\
\text { cating pill burden, side effects, } \\
\text { patient specific factors). } \\
\text { - Recognize and screen for med- } \\
\text { ications associated with delir- } \\
\text { ium and falls. } \\
\text { Communicate } \\
\text { changes, discontinuations or } \\
\text { new prescriptions with } \\
\text { patients upon discharge. }\end{array}$ & $\begin{array}{l}\text { - Develop a process for perform- } \\
\text { ing comprehensive medication } \\
\text { reviews as a routine part of the } \\
\text { pre-surgical assessment. } \\
\text { - Multidisciplinary resources are } \\
\text { necessary to manage falls and } \\
\text { delirium related to inappropri- } \\
\text { ate medication therapies. }\end{array}$ \\
\hline $\begin{array}{l}\text { Infusion } \\
\text { Center } \\
\text { Setting }\end{array}$ & $\begin{array}{l}\text { Ensure cancer therapy is appro- } \\
\text { priate based on patient's disease, } \\
\text { functional age, comorbidities, } \\
\text { and goals of care. } \\
\text { - Provide education to patients } \\
\text { regarding their regimen and } \\
\text { particular side effects that may } \\
\text { be more common based on } \\
\text { their functional age. } \\
\text { Educate infusion center staff on } \\
\text { ways to identify PIMs in older } \\
\text { adults (eg, Beer's criteria, } \\
\text { STOPP/START criteria, review } \\
\text { high risk medications). }\end{array}$ & $\begin{array}{l}\text { Assess the appropriateness of } \\
\text { cancer therapy based on } \\
\text { patient's disease, functional age, } \\
\text { comorbidities, and goals of care. } \\
\text { Evaluate effectiveness of therapy } \\
\text { and supportive care regimens, } \\
\text { and deprescribe agents in which } \\
\text { the risks outweigh the benefit. }\end{array}$ & $\begin{array}{l}\text { - Assess patient before cancer } \\
\text { therapy (infusions) to ensure } \\
\text { treatment parameters are met. } \\
\text { Ensure appropriate line access } \\
\text { for treatment. } \\
\text { - Assess patient during and after } \\
\text { infusion, monitoring for side } \\
\text { effects or reactions. } \\
\text { Communicate medication } \\
\text { changes, discontinuations, or } \\
\text { new prescriptions with } \\
\text { patients. }\end{array}$ & $\begin{array}{l}\text { Work with an interdisciplinary } \\
\text { team to develop a process to } \\
\text { review medications and cancer } \\
\text { therapy to ensure treatment is } \\
\text { appropriate for each patient } \\
\text { based on their individual factors. } \\
\text { - Communicate medication } \\
\text { changes, discontinuations or } \\
\text { new prescriptions with patients, } \\
\text { while providing thorough } \\
\text { education. }\end{array}$ \\
\hline
\end{tabular}

(Continued) 
Table I (Continued).

\begin{tabular}{|c|c|c|c|c|}
\hline $\begin{array}{l}\text { Practice } \\
\text { Setting }\end{array}$ & Pharmacy Tasks & Provider Tasks & Nursing Tasks & $\begin{array}{c}\text { Bottom Line } \\
\text { Recommendation }\end{array}$ \\
\hline $\begin{array}{l}\text { Community } \\
\text { Hospital } \\
\text { Setting }\end{array}$ & $\begin{array}{l}\text { Perform comprehensive medica- } \\
\text { tion review in order to optimize } \\
\text { medication use and minimize risk } \\
\text { of adverse drug events (eg, } \\
\text { assessing indication, limiting side } \\
\text { effects, limiting drug-drug inter- } \\
\text { actions, assessing cost, limiting pill } \\
\text { burden) } \\
\text { Evaluate cancer-related medica- } \\
\text { tions and medications for other } \\
\text { comorbid conditions. } \\
\text { Ensure chemotherapy orders } \\
\text { are verified appropriately based } \\
\text { on appropriate dosing and per- } \\
\text { tinent laboratory values. }\end{array}$ & $\begin{array}{l}\text { Develop a process to double } \\
\text { check the appropriateness of } \\
\text { cancer therapy based on } \\
\text { patient's disease, functional age, } \\
\text { comorbidities, and goals of care. }\end{array}$ & $\begin{array}{l}\text { Promote proactive medication } \\
\text { reviews for patients. } \\
\text { Work collaboratively with } \\
\text { pharmacy staff to optimize } \\
\text { medication use (eg, communi- } \\
\text { cating pill burden, side effects, } \\
\text { patient specific factors). } \\
\text { Communicate medication } \\
\text { changes, discontinuations or } \\
\text { new prescriptions with } \\
\text { patients upon discharge. }\end{array}$ & $\begin{array}{l}\text { - Collaborate with an interprofes- } \\
\text { sional team to ensure cancer } \\
\text { therapy and supportive care } \\
\text { regimens are appropriate. }\end{array}$ \\
\hline $\begin{array}{l}\text { Palliative } \\
\text { Care and } \\
\text { Hospice } \\
\text { Setting }\end{array}$ & $\begin{array}{l}\text { - Align medication decisions with } \\
\text { knowledge of patient life expec- } \\
\text { tancy and individual medication } \\
\text { goals (eg, avoidance of sedating } \\
\text { medications early in the day to } \\
\text { promote alertness). } \\
\text { - Consider patient's ability to } \\
\text { swallow or chew and the } \\
\text { impact on medication dosage } \\
\text { form decisions (eg, loss of oral } \\
\text { access necessitating sublingual } \\
\text { administration). } \\
\text { Approach deprescribing deci- } \\
\text { sions systemically in an effort } \\
\text { to minimize deprescribing fail- } \\
\text { ures and unwanted hospital } \\
\text { readmissions; support decisions } \\
\text { using standardized deprescribing } \\
\text { frameworks. }\end{array}$ & $\begin{array}{l}\text { Deprescribe medications based } \\
\text { on remaining life expectancy of } \\
\text { the patient, time until benefit of } \\
\text { the medication, individual } \\
\text { patient goals of care, and the } \\
\text { intended target of the } \\
\text { treatment. } \\
\text { - Establish roles and responsibil- } \\
\text { ities of deprescribing efforts } \\
\text { amongst provider colleagues (eg, } \\
\text { assigning ownership to primary } \\
\text { care provider versus } \\
\text { oncologist). } \\
\text { Empower nursing colleagues to } \\
\text { take the lead in flagging medica- } \\
\text { tion related problems; empower } \\
\text { through communication and } \\
\text { protocol development. }\end{array}$ & $\begin{array}{l}\text { Monitor for signs of new med- } \\
\text { ication adverse effects or } \\
\text { withdrawal symptoms after } \\
\text { deprescribing. } \\
\text { - Educate patients and caregivers } \\
\text { on potential medication } \\
\text { adjustments, monitoring, and } \\
\text { the appropriate use of "emer- } \\
\text { gent" therapies. } \\
\text { Consider patient's ability to } \\
\text { swallow or chew and the } \\
\text { impact on medication dosage } \\
\text { form decisions (eg, loss of oral } \\
\text { access necessitating sublingual } \\
\text { administration). } \\
\text { Collaborate with pharmacists } \\
\text { to develop rationale for medi- } \\
\text { cation management to present } \\
\text { to the team. }\end{array}$ & $\begin{array}{l}\text { - Align medication therapies with } \\
\text { goals of care, particularly utiliz- } \\
\text { ing therapies that improve or } \\
\text { maintain quality of life. } \\
\text { - Utilize strategies for deprescrib- } \\
\text { ing that prevent medication } \\
\text { withdrawal and unwanted emer- } \\
\text { gency department visits and } \\
\text { hospital readmissions. } \\
\text { - Explore the role of nurses in } \\
\text { medication management in the } \\
\text { palliative and hospice setting, } \\
\text { particularly nursing-pharmacist } \\
\text { collaboration. }\end{array}$ \\
\hline $\begin{array}{l}\text { Specialty } \\
\text { Pharmacy } \\
\text { Setting }\end{array}$ & $\begin{array}{l}\text { Perform comprehensive medica- } \\
\text { tion review in order to optimize } \\
\text { medication use and minimize the } \\
\text { use of } \\
\text { - PIMs. } \\
\text { motherapy and/or supportive } \\
\text { care regimens, highlighting side } \\
\text { effects or special considerations } \\
\text { (eg, drug storage, how medica- } \\
\text { tion is best taken). } \\
\text { - Discuss affordability and ensure } \\
\text { delivery of medications. } \\
\text { Assess medication adherence by } \\
\text { talking with the patient and } \\
\text { reviewing refill history. }\end{array}$ & $\begin{array}{l}\text { Assess the appropriateness of } \\
\text { cancer therapy based on } \\
\text { patient's disease, functional age, } \\
\text { comorbidities, and goals of care. } \\
\text { Communicate with specialty } \\
\text { pharmacy staff when changes } \\
\text { occur in the patient's cancer } \\
\text { regimen (eg, dosage changes, } \\
\text { start of new medications, dis- } \\
\text { continuation of medications). }\end{array}$ & $\begin{array}{l}\text { Collaborate and communicate } \\
\text { with specialty pharmacy staff } \\
\text { regarding medication changes, } \\
\text { discontinuations or new } \\
\text { prescriptions. } \\
\text { Promote medication } \\
\text { adherence. }\end{array}$ & $\begin{array}{l}\text { - Collaborate with an interprofes- } \\
\text { sional team to } \\
\text { ensure cancer therapy and sup- } \\
\text { portive care regimens are } \\
\text { appropriate. } \\
\text { - Provide thorough education and } \\
\text { assess medication adherence } \\
\text { and ensure affordability and } \\
\text { access to medications. }\end{array}$ \\
\hline
\end{tabular}




\section{Academic Medical Center Inpatient Setting}

Many patients who are hospitalized - especially patients with cancer-are taking multiple medications, including medications that are no longer needed or that potentially contribute to hospital admission or readmission. ${ }^{9}$ The inpatient academic medical center (AMC) setting presents challenges and barriers to polypharmacy assessment and deprescribing. ${ }^{10-13}$ For example, inappropriate prescribing inertia is common in the inpatient setting, and polypharmacy assessment and deprescribing are commonly limited to reactive processes, such as in response to an adverse drug reaction, rather than proactive, especially in teaching hospitals. ${ }^{14}$

But AMCs may also offer an ideal environment for deprescribing due to the collaborative environment, time for detailed medication histories, and engagement of families and caregivers in the deprescribing process during the hospital stay. ${ }^{15,16}$ For older adults with cancer, the AMC can be an appropriate environment to study polypharmacy due to the multidisciplinary cancer care, focus on education/scholarship, and longer lengths of stay. Furthermore, research in the general geriatric population has shown that inpatient deprescribing initiatives are feasible and safe and that they are successfully continued after hospital discharge. ${ }^{10}$

There is currently a literature gap on the impact of polypharmacy and deprescribing interventions specifically in the AMC. The only study on the impact of a multidisciplinary team to reduce polypharmacy in older adults with cancer is an observational study by Flood et al. ${ }^{17}$ The study outlined a model for combating polypharmacy within a novel Oncology-Acute Care for Elders (OACE) unit that served as an interdisciplinary consultation service aimed at recognizing and managing geriatric syndromes. The OACE team consisted of bedside nursing and a geriatric clinical nurse specialist, hospice nurse, geriatrician, clinical pharmacist, registered dietician, social worker, and case manager. A key component of the OACE was formal ongoing education, provided mostly by the clinical pharmacist, on geriatric syndromes, polypharmacy, and the use of high-risk medications. Researchers used the Beers Criteria to assess for PIMs and noted non-Beers medications as high-risk based on perceived likelihood of causing harm (eg, delirium, falls). The most commonly prescribed PIM was diphenhydramine. Out of 47 patients in the study, $53 \%$ had their medication regimen altered and about a third had a PIM discontinued. This model could be modified even further to create an inpatient polypharmacy consultation service or be formally integrated with inpatient rounding services for oncology units.

Other studies on the impact of polypharmacy in hospitalized patients with cancer include a small pilot study by Mort et $\mathrm{a}^{18}$ that evaluates a pharmacist-led deprescribing intervention in hematopoietic stem cell transplant patients. The pilot study was designed as a result of internal quality data showing that the inpatient stem cell transplant population experienced a high incidence of falls, mostly attributed to medication-related adverse effects (eg, delirium, vasovagal falls). ${ }^{19}$ The average age of patients in this study was 65 years old and the median length of admission was 21 days. The major endpoints of the study included incidence of PIMs, percentage of PIMs successfully deprescribed, incidence of drug-drug interactions (DDIs), comparison of home and discharge polypharmacy, and fall events. Patients were screened for polypharmacy ( $\geq 5$ medications) and PIMs (using sequential application of Beers, STOPP, and the MAI) during an outpatient pre-transplant visit. After admission, the pharmacist completed a fivestep deprescribing process. A total of 33 PIMs were identified for nine patients. Of these, a total of 22 of the 33 PIMs (67\%) were successfully deprescribed. Most common drug classes deprescribed were analgesics and vitamins/minerals. Sixteen drug interactions were noted, most commonly between ciprofloxacin and vitamins/minerals. After the deprescribing intervention for the nine patients, polypharmacy was reduced by $11 \%$ from admission to discharge. No patients in the study experienced a fall event. This was the first study to apply a deprescribing intervention in the hospital setting for patients undergoing stem cell transplant.

Several studies have described the impact of specific medications or medication classes on delirium in older adults with cancer in the AMC. One study evaluating geriatric syndromes on an OACE found that several patients were taking high-risk medications, including diphenhydramine to prevent infusion reactions prior to anticancer treatments or as part of transfusion protocols. Diphenhydramine in hospitalized older adults has been associated with an increase in urinary retention and delirium. The authors noted that the majority of the OACE patients who received diphenhydramine prior to a blood transfusion did not have a history of any infusion reaction. ${ }^{20}$ Another study by Gaudreau et $\mathrm{al}^{21}$ found that 
exposure to opioids, benzodiazepines, and corticosteroids was associated with an increased risk of delirium in hospitalized older adults with cancer. This study did not find an association with anticholinergic therapies and delirium risk.

A review by Marvin and Jubraj ${ }^{22}$ explored polypharmacy in the hospital environment in the general older adult population and found that ordering medications was the most common intervention that occurs in the acute care setting. The authors identified several points of care during a hospital stay in which a polypharmacy assessment may occur: pre-admission to the hospital, before and after surgical procedures, worsening of long-term conditions, diagnosis and treatment of a new disease alongside other preventative therapies, and preparing for hospital discharge. Each of these points of care could be explored further in older adults with cancer.

Several other studies touch upon the issue of polypharmacy that have the potential to be new areas of research for older adults with cancer, specifically in academic medical centers, including the development of health system standard work/guidance tools for inpatient polypharmacy management; the need for educating new clinicians and students about polypharmacy and its harms; the role of empowering patients to become engaged with inpatient medication reviews; and creating awareness that deprescribing is an option for patients in the hospital. ${ }^{23-28}$ More studies are also needed to define the potential roles of non-pharmacist clinicians (eg, physicians, advanced practice providers, nurses) on tackling polypharmacy. Of note, collaborative deprescribing interventions that include patients, physicians, and pharmacists may be more effective than less-inclusive interventions. ${ }^{29}$

\section{Academic Medical Center Ambulatory Care Setting}

Several barriers to polypharmacy assessment may exist in the AMC outpatient setting compared to the inpatient setting, including clinicians having less available time to spend with the patient and fewer personnel being available to complete the medication review. But the ambulatory setting within an AMC provides multiple opportunities to assess polypharmacy and other medication-related concerns in older adults with cancer. These opportunities include medication review by a nurse or doctor during a routine oncology visit; a targeted review by a pharmacist integrated into the oncology clinic; and a polypharmacy assessment in a multidisciplinary clinic that includes a pharmacist. Exactly when and how to incorporate the polypharmacy-related medication review, however, can vary.

Studies have demonstrated different approaches to accomplishing polypharmacy assessment in older adults with cancer in the ambulatory setting. In one pilot study by Ramsdale et al, ${ }^{30}$ older adults with cancer were administered a geriatric assessment (the provider performing the polypharmacy assessment was not indicated) and then the patient's oncologist either received the polypharmacy recommendations and was provided time to discuss them with the patient (intervention group) or they did not receive the recommendations (control). Despite the small number of patients $(n=40)$, the assessment identified a significant number of polypharmacy-related concerns. The majority of polypharmacy concerns centered around supportive care (51\% vs $27 \%$, respectively) but it is also worth noting that there was a notable difference in the discussion surrounding treatment for other comorbidities outside of cancer in the intervention arm (52\% vs $31 \%)$. The fact that comorbidities were not discussed as often in the control arm could imply that providers may be limited with time and therefore unable to address polypharmacy during a routine visit. Additionally, the findings indicate that polypharmacy is more likely to be addressed if the medication review can be done ahead of time or by another provider, such as a pharmacist, since routine visits rarely allow time for such assessment by the oncologist.

Other research similarly indicates the benefits of scheduling time for a medication review that occurs separately from other medical care. Yeoh et al examined the impact of a medication therapy management (MTM) service for ambulatory patients who were 65 or older and found that the clinical pharmacist performing the medication review with a validated screening tool identified a drug-related problem in at least $90 \%$ of the patients who took one or more chronic medications. ${ }^{31}$ The pharmacist intervened on 44 of the 361 identified drug-related problems, with most interventions rating some degree of significance (ranging from minor significance to very significant). These findings indicate that any older adult with cancer who is taking at least one medication is a good candidate for a more detailed polypharmacy assessment with a screening tool.

Several studies have compared the tools used to assess polypharmacy in older adults in the ambulatory setting, ${ }^{32,33}$ but few have investigated which tools are best suited for those with cancer. One study by Whitman 
et al compared the use of 12 screening assessments in older adults with cancer and found that while many of the screening tools detected PIMs, these medications may actually be benefiting the patient and therefore must be considered within the overall context. ${ }^{8}$ The authors concluded that there is a lack of polypharmacy assessment and deprescribing protocols available to target the unique population that is older adults with cancer. The findings also lend support to having a pharmacist perform the medication review, select the most appropriate screening tools, and interpret their findings.

Findings of other studies have also demonstrated the benefit of using pharmacists to perform medication reviews. For instance, a study by Nightingale et al found that some screening tools are best used in combination (eg, Beers and STOPP) to capture a larger prevalence of polypharmacy that can then be intervened upon. ${ }^{6}$ When a pharmacist, trained to be familiar with the context and indications for a medication, used a combination of validated screening tools, more PIMs were identified and rectified. This recommendation is supported by the findings of a pilot study by Whitman et al in which a pharmacist implemented a comprehensive geriatric assessment of up-to-date and accurate medication lists (including prescription, non-prescription, and supplements/complementary alternative medications) for older adults with cancer in the outpatient setting. ${ }^{5}$ The assessment utilized three screening tools, applied in the following order, as the scope of each one narrows: the Beers Criteria, Screening Tool to Alert doctors to Right Treatment (START), STOPP, and the MAI. The authors concluded that use of all three screening tools uncovered three times more drug therapy problems than any single tool alone and produced the most efficient strategy to identify inappropriate medication use. The authors also noted that supplemental screening tools, such as the Choosing Wisely Initiative and the Canadian Deprescribing Network, can further assist providers with addressing polypharmacy in older adults with cancer.

Literature supports integrating a pharmacist into ambulatory healthcare teams. A study by Valgus et al evaluated patients' palliative symptom scores over time following integration of a clinical pharmacist on an oncological multidisciplinary team in the outpatient setting. ${ }^{34}$ The study had a limited number of patients $(\mathrm{n}=89)$, with only 19 older than 60 years old. The pharmacists in the study obtained cognitive assessments, gathered medication histories, and assigned palliative assessment scores. Patient symptom evaluation was limited to palliative symptoms, not all comorbid conditions. Still, when the researchers compared the symptom scores to those from the inpatient setting, the scores in the outpatient setting improved after a pharmacist was included on the team, highlighting the value of a pharmacist-embedded in the multidisciplinary approach to treating patients.

In similar study by Mancini, a pharmacist in a multidisciplinary oncology clinic assessed the medications for adult outpatients with cancer and identified duplicate therapies ( $46.7 \%$ of patients), drug interactions (44\%), side effects (74.7\%), lack of efficacy (94.7\%), and untreated conditions (73.3\%). ${ }^{35}$ The authors concluded that a pharmacist can bring value to an outpatient team and help other practitioners with their assessments. Again, their findings support pharmacists in the medication review role, but because the population under investigation was not older adult-specific, this study did not provide direct evidence of their value for assessing polypharmacy in older adults with cancer in the ambulatory setting.

A recent study by Choukroun et al highlights the importance of collaboration among different providers for reducing polypharmacy and inappropriate medication use. ${ }^{36}$ The prospective study evaluated the impact of having a pharmacist and a geriatrician each perform a separate medication review as part of a geriatric assessment in older adults (median age: 83 years) with solid tumor malignancies and an average of four comorbidities. The notable difference between the pharmacist and geriatrician was that the pharmacist used two validated screening tools as part of the assessment. The pharmacists identified 165 drug therapy problems, most of which were moderately $(49 \%)$ or most severe $(0.8 \%)$. The authors concluded that adding a pharmacist to a geriatrician's team resulted in identification of more drug-related problems versus the experienced clinician conducting the medication review alone.

Another study by Watkins et al examined the feasibility of having pharmacists document MTM activities and subsequently bill for the service. ${ }^{37}$ The pharmacists, who were already integrated within the ambulatory clinics at the comprehensive cancer center, performed 239 MTM visits over 3 months with patients (average age $=56 \pm 13$ years) who had an oncological diagnosis and at least two other comorbidities. Many of the visits were initiated due to cancer-related concerns, but this opened the door to assessment of the patient's other comorbidities so that the patient received a comprehensive evaluation from a medication 
perspective. Implementing the formal MTM documentation and billing process increased the perceived value and visibility of the pharmacist services to the cancer center. These findings also highlight the importance of addressing not only the primary cancer but also the other comorbidities that patients may be experiencing. Although not specifically reported in this article or other available literature, it can be speculated that medication evaluation beyond cancer treatment could translate into a reduced risk of hospital admission secondary to poor management of other disease states. More literature specifically on older patients with cancer is needed.

In the ambulatory setting, there are many opportunities for patients to interact with a variety of healthcare professions. Plenty of data support integration of a pharmacist into the geriatric assessment of older adults with cancer, similar to inpatient oncology polypharmacy assessment, but it is unclear how pharmacists can best support and be supported by other members of the team for a true multidisciplinary approach that optimizes the care of older adults with cancer. Furthermore, a literature gap exists on how to best utilize non-pharmacists members of the ambulatory healthcare team in geriatric assessment. There would also be potential benefit in evaluating older adults with cancer from not only an oncological perspective but also from a cancer plus comorbidity perspective to enhance quality of life and decrease potential adverse effects.

\section{Surgical Oncology Setting}

The importance of assessing polypharmacy in older adults with cancer also applies to surgical oncology as emerging evidence suggests that polypharmacy and PIM use are significantly associated with postoperative outcomes (eg, postoperative complications, delirium, extended length of hospitalization, and emergency department visits). Thus, a unique opportunity exists for members of the interprofessional surgical oncology healthcare team to optimize medication use in order to positively impact patient care. A retrospective cohort study by Jeong et al evaluated associations between preoperative medication use and postoperative length of hospital stay in older adults undergoing cancer surgery. ${ }^{38}$ An interprofessional care team, consisting of geriatricians, nurse specialists, dietitians, and pharmacists, conducted a comprehensive preoperative geriatric assessment. The pharmacists were responsible for performing the medication assessment and evaluating all prescription and non-prescription medications, including using the 2015 Beers criteria to analyze the number of medications, delirium-inducing medications, fall-inducing medications, and PIMs. The study reported that cancer type and the number of medications, PIMs, and deliriuminducing medications were statistically significant factors for postoperative length of stay. A similar retrospective study by Choi et al examined the relationship between preoperative medication use and postoperative institutionalization and death in older adults with cancer. ${ }^{39}$ The study showed that polypharmacy, infection, and transfusions - identified on a preoperative comprehensive geriatric assessment conducted by an interprofessional care team, including pharmacists conducting the medication evaluation-were significantly associated with postdischarge institutionalization after adjusting for confounders. A study by Westley et al investigated rates and associated predictors of emergency department visits in older women 45 -days post breast cancer surgery. ${ }^{40}$ Some of the significant factors associated with emergency department visits were cancer stage, mastectomy, polypharmacy, benzodiazepine and anticoagulant use, and past hospitalization. The authors concluded that some of these factors could potentially be mitigated and amenable to early intervention. Another study by Jeon et al examined the association between preoperative medication use and hospital readmission. ${ }^{41}$ The authors reported that preoperative discontinuation-requiring medications (defined as medications that should be discontinued before surgery due to surgical risks, such as antithrombotic agents for postoperative hemorrhage, metformin for lactic acidosis, and herbal medications for the uncertainty about their actual contents) were associated with unplanned 30-day hospital readmission after surgery, despite discontinuing medications.

The International Society of Geriatric Oncology developed a Surgical Taskforce that conducted a survey to explore surgical oncologists' approach towards surgery in older adults with cancer, given the ongoing uncertainty around cancer management, including under-treatment and overtreatment. ${ }^{42}$ The survey reported a low overall response rate $(11 \%, \mathrm{n}=251)$ and revealed that only $6.4 \%$ of the surgeons who responded used a comprehensive geriatric assessment in daily practice. Additionally, collaboration with geriatricians was uncommon, despite the fact that patient quality of life and functional recovery were identified as some of the most important and relevant endpoints in this population. 
Combined, this information presents an opportunity for oncology surgery service lines to reimagine how interprofessional team members and resources can be utilized to improve patient outcomes. Little research has focused on medication interventions to reduce polypharmacy and optimize medication management in older adults with cancer in the surgical oncology (preoperative) setting. ${ }^{5,6,43-46} \mathrm{But}$ it is clear that medication management is a critical component of the preoperative screening assessment and the postoperative monitoring process. At a minimum, preoperative medication assessments should consist of an evaluation for polypharmacy and inappropriate polypharmacy. Inappropriate polypharmacy can be screened utilizing tools such as Beers criteria ${ }^{47}$ or the STOPP criteria. ${ }^{48}$ Both delirium- and fall-inducing medications should be identified, with indications for use, so potential deprescribing could be initiated. In such cases, deprescribing could consist of dose tapering, switching to as-needed use, or abrupt discontinuation with pre-determined monitoring parameters for close follow-up. Additional medications that should be assessed and discontinued as part of the preoperative process include antithrombotic agents due to risk for hemorrhage, metformin due to risk for lactic acidosis, exogenous hormones due to risk for thrombosis, and herbal medications due to uncertainty around actual contents and risk for drug-herb interactions. ${ }^{38}$

Delivering comprehensive medication management services within a surgical oncology practice environment does require significant resources, including staff/personnel, time, finances and leadership to oversee this highquality service. Although these resources may add costs and time to care initially, they may also provide valuable benefits postoperatively in the form of improved patient outcomes and reduced readmissions rates.

\section{Infusion Center Setting}

In infusion centers, pharmacists are involved in the preparation and dispensing of chemotherapy regimens, and they also have the opportunity to play a role in identifying PIMs in older adults with cancer. It is important for these pharmacists to be aware of not only a patient's chronological age but also a patient's functional age when assessing appropriateness of the patients' regimens. In 2018, the Hematology/Oncology Pharmacy Association published guidelines that further defined the scope of hematology/ oncology practice for pharmacists, including the role of infusion center pharmacists. ${ }^{49}$ The document outlines important tasks of the infusion center pharmacist, including upholding, maintaining regulation requirements, and reviewing a patient's cancer treatment plan through verification and dispensing processes. The document does not, however, address concerns related to older patients with cancer.

Limited research has explored the role of infusion center pharmacists in medication use and assessment. In a prospective, descriptive, cross-sectional study by Knez et al, pharmacists in a chemotherapy preparation unit were shadowed to evaluate the clinical interventions they made related to the dispensing of chemotherapy doses. ${ }^{50}$ The problems that the pharmacist identified as requiring an intervention mostly related to "drug and therapy" (38\%), "clerical" (33\%), or "dose, frequency, and duration" (19\%). The oncologist accepted most pharmacist recommendations, implementing them in $86 \%$ of the cases. These findings highlight the important role of pharmacists in reviewing the treatment plan and dispensing of the chemotherapy in order to provide quality care to patients with cancer. The study did not discuss the importance of a full medication review that included reviewing a patient's non-cancer medication regimen, particularly in the older cancer patient population (patients in this study ranged in age from 24 to 75 years).

A retrospective cohort study by Sokol et al aimed to identify the potential for adverse drug reactions and to define physicians' responses to potential DDIs in patients at least 70 years of age with multiple comorbidities and also receiving chemotherapy. On average, patients had three comorbid conditions, most commonly cardiovascular, pulmonary, and gastrointestinal conditions. The results showed that polypharmacy was prevalent in these patients, as they took an average of nine medications (prescription and non-prescription), most commonly medications for treating cardiovascular and gastrointestinal comorbidities. Despite the potential for DDIs, physicians made no adjustments to prescriptions. ${ }^{51}$

Additional studies are needed to further define the role of the pharmacist in the infusion center setting, particularly related to polypharmacy and the care of older adults with cancer. Likewise, studies could also be conducted to define the role of other healthcare providers and how to best collaborate in the infusion center setting.

\section{Community Hospital Setting}

Community cancer centers differ from larger AMCs and designated cancer cancers in regard to resources and staff. In particular, community cancer centers often lack 
a clinical pharmacist who can provide medication assessment specific to the issues facing patients with cancer. The literature describing older adult cancer care provided at community hospitals is scarce, especially studies reporting on medication use and polypharmacy. A retrospective study by Loui et al demonstrated that complex oncologic resections (defined as esophagogastric, hepatobiliary, pancreatic, rectal, and retroperitoneal resections) could be safely performed at community hospitals. ${ }^{52}$ Of the patients evaluated, $88(64.7 \%)$ were male and average age was 65.6 years. The mortality rate was $0.7 \%$ (grade $\mathrm{V}$ complication), the median length of stay for all operations was 8 days, and the hospital readmission rate within 30 days of initial discharge was $2.9 \%$. The authors did not discuss medication assessments nor did they discuss inappropriate polypharmacy, delirium or falls as part of the study outcomes. A similar study by Hardacre et al evaluated 60-day outcomes associated with a pancreatic surgery program at a 144-bed community, non-teaching hospital compared to a tertiary medical center. ${ }^{53}$ The authors reported that there were no mortalities at either hospital, and major complications, reoperation rates, and readmission rates did not differ between the two hospitals. ${ }^{53}$ They did not report preoperative medication assessments nor delirium or falls as part of the study outcomes.

A study by Chung et al reported on a practice model change within a community hospital aimed to meet quality and safety goals. ${ }^{54}$ The practice change involved an interprofessional team of nurses, pharmacists, and physicians that developed standardized order sets, protocols, operations, and chemotherapy, along with collaborative practice agreements. This practice model change resulted in a $45 \%$ reduction in chemotherapy errors and found that the most common cause of errors was missing information (eg, omission of drug duration or frequency, dose, route, or premedication). The pharmacists reported that, prior to the practice model change, they did not feel empowered to make clinical recommendations on dose modification or provide specific oncology drug information, and after the changes were implemented, they had the tools to perform clinical monitoring and communicate recommendations to oncology physicians and providers. ${ }^{54}$ This study did not include information on structured medication assessments for non-chemotherapy drugs and did not report how the practice model change influenced patient outcomes.

We also uncovered literature on the development of a senior adult oncology program within a community cancer center. A pilot study by Lynch et al described the development of a specialized program for older adults within a community cancer center. ${ }^{55}$ The program was designed to identify and treat cancer and comorbidities, geriatric syndromes such as malnutrition and polypharmacy, and educate patients, families, and the community, among other goals. ${ }^{55}$ It consisted of a unique model of service including a nursing assessment, social work evaluation, psychological evaluation, nutrition counseling, and prescription guidance, however the program did not mention whether a pharmacist was a member of the interprofessional care team. The patients who participated in the pilot experienced a variety of medical issues, with the most common related to nutrition $(n=19)$ and medication assistance $(n=130) .{ }^{55}$ Details regarding polypharmacy were not included, and medication-related interventions were not reported.

Recognizing that community cancer centers may not have the same amount of resources or number of cancer care providers, specialists, and allied healthcare professionals (eg, clinical pharmacists, dieticians, social workers, care navigators), few studies have evaluated the benefit of clinical pharmacy services at a community oncology clinic. A retrospective descriptive study by Ruder et al analyzed the impact and cost savings of having a clinical pharmacist on staff to consult regarding clinical interventions and consultations at a community oncology clinic. ${ }^{56}$ Interventions included medication reconciliation, dosing, and side effect prevention and management, and consultations involved patient visits and patient education. Of the 583 interventions reported, 131 were related to adverse events, 52 were related to medication reconciliation, and 22 were dose-related. Patient et al surveys revealed positive ratings for clinical pharmacy services. ${ }^{56}$ This study did not report patient demographic information, such as median age, and did not include information on polypharmacy and inappropriate polypharmacy. The study did, however, demonstrate that the presence of a clinical pharmacist (versus a pharmacist who is solely responsible for admixing and dispensing parenteral chemotherapy) opens up opportunities to optimize the quality of cancer care for patients and to improve drug information and education to fellow healthcare providers.

\section{Palliative Care and Hospice Setting}

Many clinicians are daunted by the prospect of managing polypharmacy and PIMs in persons who are nearing or are at the end of life. ${ }^{57}$ Cancer care and medication management in this population is complex due to a number of 
different factors. These include a rise in the number of comorbidities at the end of life, an increase in the potential for medication adverse effects and geriatric syndromes, conflicting goals of care between providers and patients, and poor approximation of life expectancy. The incidence of PIM use in older adults with cancer, specifically in the palliative care and hospice settings, has been found to range from $22 \%$ to $95 \% .{ }^{58}$ However, the criteria for PIM identification, as well as the process for deprescribing, are inconsistent between studies. Outcomes data are also sparse in this population. ${ }^{59-61}$

Despite these limitations, several deprescribing frameworks have been developed that provide an opportunity for future research in older adults with cancer. A framework developed by Lindsay et $\mathrm{al}^{62}$ aims specifically to assist clinicians in recognizing PIMs and guide rational deprescribing in palliative oncology patients. Called OncPal, the guideline is geared towards patients with a life expectancy of less than 6 months; therefore, it is applicable in both the palliative and hospice settings. The initial study compared the use of the OncPal Deprescribing Guideline to expert assessment (palliative care, radiation oncology, and medical oncology clinicians) and found that the OncPal guideline assessed PIMs correctly $94 \%$ of the time comparatively. The incidence of PIMs in this study was $70 \%$, with the most frequently flagged drug classes for deprescribing intervention being antihypertensives, dyslipidemic agents, and complementary and alternative therapies. The medication class found to be the most discordant between the OncPal guideline and the expert panel was neoplastic/immunomodulator oral anticancer treatments. Preliminary data suggest an important role of the OncPal deprescribing guideline, yet additional studies are needed to validate its use in different care settings.

The Good Palliative-Geriatric Practice (GP-GP) algorithm is a well-validated tool potentially applicable to older adults with cancer in the palliative care setting. The tool consists of a number of targeted statements questioning medication appropriateness. An initial study by Garfinkel ${ }^{63}$ using the GP-GP algorithm focused on reducing polypharmacy in older adults in geriatric inpatient units. The algorithm was applied in 119 patients (intervention group) versus 71 patients in a control, nonintervention group. A total of 332 medications were deprescribed in the 119 patients, averaging 2.8 medications per patient, and the rate of deprescribing failure was $10 \%$. The 1 -year mortality rate was $21 \%$ in the intervention group versus $45 \%$ in the control group, and the rate of referral to a higher level of care was $11.8 \%$ in the intervention group versus $30 \%$ in the control group. ${ }^{63}$ A subsequent study by Garfinkel ${ }^{64}$ validated the use of the GP-GP algorithm in community-dwelling older adults. This study excluded patients with advanced disease (including cancer), thus reducing generalizability to the geriatric oncology population. Finally, a study by Bilek et $\mathrm{al}^{65}$ found that providing physicians a one-day workshop on the use of the GP-GP algorithm successfully promoted deprescribing efforts in both the inpatient and outpatient setting. Trained physicians had a high incidence of deprescribing benzodiazepines, psychotropics, and antihypertensives. About a quarter of patients in this study were older adults with cancer.

A deprescribing framework by Holmes et $\mathrm{al}^{66}$ has been applied to older adults with cancer. This model uses four "pillars" of medication appropriateness to determine correct prescribing and deprescribing: remaining life expectancy of the patient, time until benefit of the medication, individual patient goals of care, and the intended target of the treatment (eg, palliative in nature vs preventative care). The framework by Holmes et al $^{66}$ has been utilized in at least one study in older adults with cancer. ${ }^{5}$ This study was multidisciplinary in nature and included input on the four components of medication appropriateness by a geriatric oncologist, pharmacist, nurse, physical therapist, and patients/caregivers.

In addition to applicable frameworks in the palliative oncology population, specific studies have assessed the impact of reducing pill burden and eliminating unnecessary medications in the hospice setting and in patients imminently dying of cancer. ${ }^{67,68}$ A study from 2009 by Riechelman et al found that one in five ambulatory patients with cancer with an estimated life expectancy of 2 months or less were taking a "futile" medication. ${ }^{59}$ The authors defined medically futile as "an intervention that no longer provides patient benefit, does not achieve a valuable goal, has a potential for harm and lacks benefits to justify resources" and retrospectively reviewed the medication lists of 372 older patients with cancer who were seen in a palliative care clinic and evaluated whether the medications they were taking were indeed futile. They found that $22 \%(n=82)$ of the patients were taking at least one futile medication at the end of life.

A retrospective review by DeAngelis et al assessed contributing factors potentially leading to hospital readmission in 75 patients admitted to hospice. The authors identified three main reasons for readmission: medication-related problems, unanticipated new medical problems, and uncontrolled 
symptoms. Interestingly, 33 of the patients (45\%) presented with uncontrolled symptoms, thereby requiring reinitiating therapy previously deprescribed upon hospice admission. ${ }^{69}$ The conclusions of this study are supported by two others, ${ }^{70,71}$ but despite this, few studies have reported outcomes of inappropriate deprescribing in the hospice population.

There is a gap in the literature describing which member(s) of the healthcare team are best equipped to manage polypharmacy and PIMs in this population. In one study that touches upon the concepts of older adults with cancer, polypharmacy, and chronic disease state management at the end of life, the authors point out that the general practitioner is often unwilling to alter cancerrelated treatment, and in turn the oncologist is often unwilling to alter any non-cancer-related treatment, thereby putting the patient at risk of continued polypharmacy with potential adverse outcomes. ${ }^{72}$ The findings of the study highlight that polypharmacy is often not addressed until the end of life and beg the question "whose responsibility is it to address polypharmacy?" The authors conclude that a patient's primary care physician should be assessing polypharmacy prior to the end-oflife phase of care.

Huisman et al recently explored the role of the hospice nurse in medication management and deprescribing interventions. $^{73}$ The authors performed a qualitative interview study to summarize perspectives of patients, caregivers, and healthcare providers on the nurse's role in medication management in the hospice setting. The study was a secondary analysis for the "MEDIcation management in the LAST phase of life (MEDILAST)" study. The authors performed 76 interviews with patients $(\mathrm{n}=17)$, nurses $(\mathrm{n}=20)$, medical trainees $(\mathrm{n}=20)$, informal caregivers $(\mathrm{n}=12)$, and family physicians $(n=12)$, and the recorded interviews were analyzed and coded based on relevancy. The notable emerging themes identified via the interviews included the nurse's role in identifying medication burden at the end of life; educating the patient on medication adjustments and the monitoring that will follow; monitoring for medication side effects; and the direct impact on quality of life. The interviews revealed that the hospice nurse plays a role in delegating medication management to the caregiver in some cases and in keeping them educated on when to administer "emergent" medications. Additionally, the hospice nurse can propose changes in medication therapy, such as the route of administration when the patient is no longer able to swallow, and empower the patient and caregivers on as-needed medication administration. Ultimately, the authors concluded that the nurse plays a large role in the patient's end-of-life medication management and quality of life.

In summary, based on available information, medication management roles for pharmacists, providers, and nurses appear balanced in the palliative oncology and hospice settings. For future studies, existing frameworks in palliative oncology should be utilized and compared across different cancer care settings, particularly emphasizing outcomes of deprescribing and deprescribing failure.

\section{Specialty Pharmacy Setting}

Specialty pharmacies have grown immensely over the past four decades, establishing their role in healthcare delivery. These pharmacies are able to work with providers and insurers alike to ensure patient access to therapy and to address issues regarding financing and delivery of the medication, including oncology medications. ${ }^{74}$ However, as these pharmacies have become more popular, patients may fill their medications at multiple pharmacies. Inadequate communication among pharmacies and providers may lead to therapeutic duplication or prescribing of medications with significant DDIs. ${ }^{75}$ This lack of communication among health care professionals may be particularly problematic for older adults with cancer who often have multiple chronic conditions and take many medications. $^{76}$

There are limited data regarding polypharmacy in older adults with cancer utilizing specialty pharmacies. However, according to the National Comprehensive Cancer Network Specialty Pharmacy Task Force, the primary goals of specialty pharmacies are to ensure the appropriate use of medications, maximize drug adherence, enhance patient satisfaction through direct interaction with healthcare professionals, minimize cost impact, and optimize pharmaceutical care outcomes and delivery of information. ${ }^{77}$ These goals can be further defined to apply to older patients with cancer. For example, ensuring the appropriate use of medications may include the use of tools such as the Beer's criteria, STOPP/START criteria and the MAI. ${ }^{77}$ Nonadherence to medication therapy can occur in all patient populations, but is particularly common in the older adult population because they have a high number of comorbid conditions. ${ }^{78}$ In patients with cancer, adherence to their anticancer and supportive care regimens is imperative to the success of their treatment course. Therefore, in older adults with cancer utilizing specialty pharmacies, the ability to assess and address nonadherence 
is particularly important. A retrospective analysis of a specialty pharmacy program by Tschida et al compared patients who used specialty pharmacies to those who used retail pharmacies for their oral cancer regimen. ${ }^{79}$ Pharmacist involvement included biweekly phone calls with the patients to assess adherence, provide education, and manage side effects. The study showed that the use of specialty pharmacy was associated with improved oral oncology medication adherence, as well as a decrease in healthcare costs. However, identifying drug-drug interactions, reviewing a patients' non-cancer medications, and assessing polypharmacy was not discussed in the study.

When a cancer patient utilizes a specialty pharmacy, that pharmacy takes on an integral role in the care of these patients as they may communicate with the patient regularly regarding their anticancer or supportive care regimen, including discussion of adverse events and toxicities. However, the use of specialty pharmacies could contribute to siloes or fragmented healthcare. It is imperative that specialty pharmacies communicate effectively and relay relevant information gleaned from their patient interactions to the patient's entire oncology team. This communication creates an opportunity for those involved in the care of these oncology patients to collaborate with specialty pharmacies to ensure that a patient has continued access to their medication and that therapy adjustments, including temporarily holding therapy, are appropriately communicated. Additionally, there may be a unique opportunity for all involved to ensure that a patient's therapy is appropriate not only for their chronological age but also their functional age including their unique social, psychosocial, and financial situations.

\section{Conclusion}

Existing data suggest a variety of clinician roles in managing polypharmacy and other medication-related problems in older adults with cancer. The impact of clinical pharmacists in this population is particularly evident in the academic inpatient, ambulatory, and palliative care settings. The extent of non-pharmacist clinician involvement varies significantly based on the care setting. Established themes for providers related to polypharmacy and deprescribing interventions include the need for enhanced awareness of potential harms of high-risk medications and the need for breaking patterns of inappropriate prescribing in all care settings. Studies evaluating nursing care suggest positive roles for empowering patients to bring forth medication concerns to their providers, flagging new potential medication side effects, and collaborating closely with pharmacy colleagues. Future studies are needed to determine ideal processes for polypharmacy assessment and deprescribing in the infusion center, specialty pharmacy, and surgical oncology settings, in particular. Additionally, structured studies are needed that examine the current state of polypharmacy education in healthcare across all health professions.

\section{Acknowledgments}

We are grateful to Jennifer Fisher Wilson (Thomas Jefferson University) for her assistance with editing this manuscript.

\section{Disclosure}

The authors report no conflicts of interest in this work.

\section{References}

1. Garfinkel D, Ilhan B, Bahat G. Routine deprescribing of chronic medications to combat polypharmacy. Ther Adv Drug Saf. 2015;6 (6):212-233. doi:10.1177/2042098615613984

2. Mangin D, Bahat G, Golomb BA, et al. International group for reducing inappropriate medication use \& polypharmacy (IGRIMUP): position statement and 10 recommendations for action. Drugs Aging. 2018;35(7):575-587. doi:10.1007/s40266-018-0554-2

3. Whitman AM. Pharmacology of aging and cancer. Geriatr Oncol. 2020. doi:10.1007/978-3-319-57415-8 65

4. Reeve E, To J, Hendrix I, Shakib S, Roberts MS, Wiese MD. Patient barriers to and enablers of deprescribing: a systematic review. Drugs Aging. 2013;30(10):793-807. doi:10.1007/s40266-013-0106-8

5. Whitman A, DeGregory K, Morris A, Mohile S, Ramsdale E. Pharmacist-led medication assessment and deprescribing intervention for older adults with cancer and polypharmacy: a pilot study. Support Care Cancer. 2018;26(12):4105-4113. doi:10.1007/s00520-018-4281-3

6. Nightingale G, Hajjar E, Swartz K, Andrel-Sendecki J, Chapman A. Evaluation of a pharmacist-led medication assessment used to identify prevalence of and associations with polypharmacy and potentially inappropriate medication use among ambulatory senior adults with cancer. J Clin Oncol. 2015;33(13):1453-1459. doi:10.1200/ JCO.2014.58.7550

7. Todd A, Jansen J, Colvin J, McLachlan A. The deprescribing rainbow: a conceptual framework highlighting the importance of patient context when stopping medication in older people. BMC Geriatr. 2018;18:295. doi:10.1186/s12877-018-0978-x

8. Whitman AM, DeGregory KA, Morris AL, Ramsdale EE A comprehensive look at polypharmacy and medication screening tools for the older cancer patient. Oncologist. 2016;21(6):723-730. doi:10.1634/theoncologist.2015-0492

9. Ostini R, Hegney D, Jackson C, Tett SE. Knowing how to stop: ceasing prescribing when the medicine is no longer required. $J$ Manag Care Pharm. 2012;18(1):68-72. doi:10.18553/jmcp.2012.18.1.68

10. Kouladjian O'Donnell L, Dearing ME. Should hospital admission be used as an opportunity for deprescribing in older adults? Can J Hosp Pharm. 2020;73(4). doi:10.4212/cjhp.v73i4.3029

11. Daliri S, Bekker CL, Buurman BM, Scholte op Reimer WJM, van den Bemt BJF, Karapinar-çarkit F. Barriers and facilitators with medication use during the transition from hospital to home: a qualitative study among patients. BMC Health Serv Res. 2019;19 (1):204. doi:10.1186/s12913-019-4028-y 
12. Scott S, Clark A, Farrow C, et al. Attitudinal predictors of older peoples' and caregivers' desire to deprescribe in hospital. $B M C$ Geriatr. 2019;19(1):108. doi:10.1186/s12877-019-1127-x

13. Komagamine J, Sugawara K, Hagane K. Characteristics of elderly patients with polypharmacy who refuse to participate in an in-hospital deprescribing intervention: a retrospective cross-sectional study. BMC Geriatr. 2018;18(1):96. doi:10.1186/ s12877-018-0788-1

14. Scott S, Clark A, Farrow C, et al. Deprescribing admission medication at a UK teaching hospital; a report on quantity and nature of activity. Int J Clin Pharm. 2018;40(5):991-996. doi:10.1007/s11096018-0673-1

15. Baysari M, Duong M, Zheng W, et al. Delivering the right information to the right person at the right time to facilitate deprescribing in hospital: a mixed methods multisite study to inform decision support design in Australia. BMJ Open. 2019;9(9):e030950. doi:10.1136/ bmjopen-2019-030950

16. Ailabouni N, Nishtala P, Mangin D, Tordoff J, Cox D. Challenges and enablers of deprescribing: a general practitioner perspective. PLoS One. 2016;11(4):e0151066. doi:10.1371/journal. pone.0151066

17. Flood KL, Carroll MB, Le CV, Brown CJ. Polypharmacy in hospitalized older adult cancer patients: experience from a prospective, observational study of an oncology-acute care for elders unit. Am $J$ Geriatr Pharmacother. 2009;7(3):151-158. doi:10.1016/j. amjopharm.2009.05.002

18. Mort MK, DeGregory KA, Reufer K, Volodin L, Whitman AM Evaluation of a pharmacist-led deprescribing intervention in stem cell transplant patients [abstract]. Hematology Oncology Pharmacy Association Annual Meeting; April 3; 2019; Fort Worth, TX.

19. Mort MK, Whitman AM, DeGregory KA, et al. Evaluation of the incidence of in-hospital falls and associated risk factors for adult patients with a hematologic malignancy [abstract]. Vizient University Health System Consortium Pharmacy Network Meeting; December 2; 2017; Orlando, FL.

20. Flood KL, Carroll MB, Le CV, et al. Geriatric syndromes in elderly patients admitted to an oncology-acute care for elders unit. J Clin Oncol. 2006;24(15):2298-2303. doi:10.1200/JCO.2005.02.8514

21. Gaudreau JD, Gagnon P, Roy MA, Harel F, Tremblay A. Opioid medications and longitudinal risk of delirium in hospitalized cancer patients. Cancer. 2007;109(11):2365-2373. doi:10.1002/cncr.22665

22. Marvin V, Jubraj B. Polypharmacy and older people in the hospital environment. Public Policy Aging Rep. 2018;28(4):150-155. doi:10.1093/ppar/pry029

23. Edey R, Edwards N, Von Sychowski J, Bains A, Spence J, Martinusen D. Impact of deprescribing rounds on discharge prescriptions: an interventional trial. Int J Clin Pharm. 2019;41(1):159-166. doi:10.1007/s11096-018-0753-2

24. Potter EL, Lew TE, Sooriyakumaran M, Edwards AM, Tong E, Aung AK. Evaluation of pharmacist-led physician-supported inpatient deprescribing model in older patients admitted to an acute general medical unit. Australas J Ageing. 2019;38(3):206-210. doi:10.1111/ ajag. 12643

25. Thillainadesan J, Gnjidic D, Green S, Hilmer SN. Impact of deprescribing interventions in older hospitalised patients on prescribing and clinical outcomes: a systematic review of randomised trials. Drugs Aging. 2018;35(4):303-319. doi:10.1007/s40266-018-0536-4

26. McKean M, Pillans P, Scott IA. A medication review and deprescribing method for hospitalised older patients receiving multiple medications. Intern Med J. 2016;46(1):35-42. doi:10.1111/imj.12906

27. Viktil KK, Blix HS, Eek AK, Davies MN, Moger TA, Reikvam A. How are drug regimen changes during hospitalisation handled after discharge: a cohort study. BMJ Open. 2012;2(6):e001461. doi:10.1136/bmjopen-2012-001461
28. World Health Organization. WHO global patient safety challenge: medication without harm. 2017. Available from: www.who.int/patient safety. Accessed April 1, 2021.

29. Steinman MA, Landefeld CS. Overcoming inertia to improve medication use and deprescribing: patients, pharmacists, and physicians. JAMA. 2018;320(18):1867-1869. doi:10.1001/ jama.2018.16473

30. Ramsdale E, Lemelman T, Loh KP, et al. Geriatric assessment-driven polypharmacy discussions between oncologists, older patients, and their caregivers. J Geriatr Oncol. 2018;9(5):534-539. doi:10.1016/j. jgo.2018.02.007

31. Yeoh TT, Si P, Chew L. The impact of medication therapy management in older oncology patients. Support Care Cancer. 2013;21 (5):1287-1293. doi:10.1007/s00520-012-1661-y

32. Price SD, Holman CD, Sanfilippo FM, Emery JD. Association between potentially inappropriate medications from the Beers criteria and the risk of unplanned hospitalization in elderly patients. Ann Pharmacother. 2014;48(1):6-16. doi:10.1177/ 1060028013504904

33. Corsonello A, Onder G, Abbatecola AM, Guffanti EE, Gareri P, Lattanzio F. Explicit criteria for potentially inappropriate medications to reduce the risk of adverse drug reactions in elderly people: from beers to STOPP/START criteria. Drug Saf. 2012;35(Suppl 1):21-28. doi:10.1007/BF03319100

34. Valgus J, Jarr S, Schwartz R, Rice M, Bernard SA. Pharmacist-led, interdisciplinary model for delivery of supportive care in the ambulatory cancer clinic setting. J Oncol Pract. 2010;6(6):e1-e4. doi:10.1200/JOP.2010.000033

35. Mancini R. Implementing a standardized pharmacist assessment and evaluating the role of a pharmacist in a multidisciplinary supportive oncology clinic. J Support Oncol. 2012;10(3):99-106. doi:10.1016/j. suponc.2011.09.005

36. Choukroun C, Leguelinel-Blache G, Roux-Marson C, et al. Impact of a pharmacist and geriatrician medication review on drug-related problems in older outpatients with cancer [published online ahead of print, 2020 Aug 13]. J Geriatr Oncol. 2020:S1879-4068(20) 30114-4. doi:10.1016/j.jgo.2020.07.010

37. Watkins JL, Landgraf A, Barnett CM, Michaud L. Evaluation of pharmacist-provided medication therapy management services in an oncology ambulatory setting. $J$ Am Pharm Assoc. 2012;52 (2):170-174. doi:10.1331/JAPhA.2012.11171

38. Jeong YM, Lee KE, Lee ES, et al. Preoperative medication use and its association with postoperative length of hospital stay in surgical oncology patients receiving comprehensive geriatric assessment. Geriatr Gerontol Int. 2018;18(1):12-19. doi:10.1111/ggi.13127

39. Choi KS, Jeong YM, Lee E, et al. Association of pre-operative medication use with post-surgery mortality and morbidity in oncology patients receiving comprehensive geriatric assessment. Aging Clin Exp Res. 2018;30(10):1177-1185. doi:10.1007/s40520-0180904-2

40. Westley T, Syrowatka A, Henault D, et al. Patterns and predictors of emergency department visits among older patients after breast cancer surgery: a population-based cohort study. J Geriatr Oncol. 2018;9 (3):204-213. doi:10.1016/j.jgo.2017.10.003

41. Jeon MS, Jeong YM, Yee J, et al. Association of pre-operative medication use with unplanned 30-day hospital readmission after surgery in oncology patients receiving comprehensive geriatric assessment. Am J Surg. 2020;219(6):963-968. doi:10.1016/j. amjsurg.2019.06.020

42. Ghignone F, van Leeuwen BL, Montroni I, et al. The assessment and management of older cancer patients: a SIOG surgical task force survey on surgeons' attitudes. Eur J Surg Oncol. 2016;42 (2):297-302. doi:10.1016/j.ejso.2015.12.004 
43. Leger DY, Moreau S, Signol N, et al. Polypharmacy, potentially inappropriate medications and drug-drug interactions in geriatric patients with hematologic malignancy: observational single-center study of 122 patients. $J$ Geriatr Oncol. 2018;9(1):60-67. doi:10.1016/j.jgo.2017.07.015

44. Kalsi T, Babic-Illman G, Ross PJ, et al. The impact of comprehensive geriatric assessment interventions on tolerance to chemotherapy in older people. $B r J$ Cancer. 2015;112(9):1435-1444. doi:10.1038/ bjc. 2015.120

45. Deliens C, Deliens G, Filleul O, et al. Drugs prescribed for patients hospitalized in a geriatric oncology unit: potentially inappropriate medications and impact of a clinical pharmacist. J Geriatr Oncol. 2016;7(6):463-470. doi:10.1016/j.jgo.2016.05.001

46. Zullig LL, Kimmick G, Smith V, et al. Using a geriatric oncology assessment to link with services (GOAL). J Geriatr Oncol. 2019;10 (1):164-168. doi:10.1016/j.jgo.2018.06.004

47. By the American Geriatrics Society 2015 Beers Criteria Update Expert Panel. American Geriatrics Society 2015 updated beers criteria for potentially inappropriate medication use in older adults. J Am Geriatr Soc. 2015;63(11):2227-2246. doi:10.1111/ jgs. 13702

48. Gallagher P, O’Mahony D. STOPP (Screening Tool of Older Persons' potentially inappropriate Prescriptions): application to acutely ill elderly patients and comparison with Beers' criteria. Age Ageing. 2008;37(6):673-679. doi:10.1093/ageing/afn197

49. Hematology/Oncology Pharmacy Association. Further defining the scope of hematology/oncology pharmacy practice. Available from: http://www.hoparx.org/images/hopa/resource-library/guidelinesstandards/HOPA18 Scope-2 Web2.pdf. Accessed April 1, 2021.

50. Knez L, Laaksonen R, Duggan C. Evaluation of clinical interventions made by pharmacists in chemotherapy preparation. Radiol Oncol. 2010;44(4):249-256. doi:10.2478/v10019-010-0040-x

51. Sokol KC, Knudesen JF, Li MM. Polypharmacy in older oncology patients and the need for an interdisciplinary approach to side-effect management. J Clin Pharm Ther. 2007;32(2):169-175. doi:10.1111/ j.1365-2710.2007.00815.x

52. Loui H, Benyamini P, Maldini G. Major oncologic surgery at a community hospital. Hawaii J Med Public Health. 2017;76(2):39.

53. Hardacre JM, Raigani S, Dumot J. Starting a high-quality pancreatic surgery program at a community hospital. J Gastrointest Surg. 2015;19(12):2178-2182. doi:10.1007/s11605-015-2937-6

54. Chung C, Collins A, Cui N. Development and implementation of an interdisciplinary oncology program in a community hospital. Am $J$ Health Syst Pharm. 2011;68(18):1740-1747. doi:10.2146/ ajhp100626

55. Lynch MP, Marcone D, Kagan SH. Developing a multidisciplinary geriatric oncology program in a community cancer center. Clin J Oncol Nurs. 2007;11(6):929-933. doi:10.1188/07.CJON.929-933

56. Ruder AD, Smith DL, Madsen MT, Kass FH 3rd. Is there a benefit to having a clinical oncology pharmacist on staff at a community oncology clinic? J Oncol Pharm Pract. 2011;17(4):425-432. doi:10.1177/ 1078155210389216

57. McPherson AL, McPherson ML. Deprescribing: right-sizing medication regimens to optimize outcomes in palliative care. Curr Geriatr Rep. 2019;8:21-30. doi:10.1007/s13670-019-0274-4

58. Lindsay J, Dooley M, Martin J, Fay M, Kearney A, Barras M. Reducing potentially inappropriate medications in palliative cancer patients: evidence to support deprescribing approaches. Support Care Cancer. 2014;22:1113-1119. doi:10.1007/s00520-013-2098-7

59. Riechelmann RP, Krzyzanowska MK, Zimmermann C. Futile medication use in terminally ill cancer patients. Support Care Cancer. 2009;17(6):745-748. doi:10.1007/s00520-008-0541-y

60. Fede A, Miranda M, Antonangelo D, et al. Use of unnecessary medications by patients with advanced cancer: cross-sectional survey. Support Care Cancer. 2011;19(9):1313-1318. doi:10.1007/ s00520-010-0947-1
61. Todd A, Husband A, Andrew I, Pearson SA, Lindsey L, Holmes H. Inappropriate prescribing of preventative medication in patients with life-limiting illness. BMJ Support Palliat Care. 2017;7(2):113-121. doi:10.1136/bmjspcare-2015-000941

62. Lindsay J, Dooley M, Martin J, et al. The development and evaluation of an oncological palliative care deprescribing guideline: the 'OncPal deprescribing guideline'. Support Care Cancer. 2015;23 (1):71-78. doi:10.1007/s00520-014-2322-0

63. Garfinkel D, Zur-Gil S, Ben-Israel J. The war against polypharmacy: a new cost-effective geriatric-palliative approach for improving drug therapy in disabled elderly people. Isr Med Assoc J. 2007;9 (6):430-434.

64. Garfinkel D, Mangin D. Feasibility study of a systematic approach for discontinuation of multiple medications in older adults: addressing polypharmacy. Arch Int Med. 2010;170(18):1648-1654. doi:10.1001/archinternmed.2010.355

65. Bilek AJ, Yuval L, Kab H, Andreev P, Garfinkel D. Teaching physicians the GPGP method promotes deprescribing in both inpatient and outpatient settings. Ther Adv Drug Saf. 2019;10:2042098619895914. doi:10.1177/2042098619895914

66. Holmes HM, Hayley DC, Alexander GC, Sachs GA. Reconsidering medication appropriateness for patients late in life. Arch Intern Med. 2006;166(6):605-609. doi:10.1001/archinte.166.6.605

67. Gardner E. Deprescribing in end-of-life care. Br J Community Nurs. 2019;24(10):474-477. doi:10.12968/bjen.2019.24.10.474

68. Riker GI, Setter SM. Polypharmacy in older adults at home: what it is and what to do about it-implications for home healthcare and hospice. Home Healthc Nurse. 2012;30(8):474-487. doi:10.1097/ NHH.0b013e31826502dd

69. DeAngelis J, Lowry MF. Hospital readmissions in hospice patients: evaluation of medication-related causes for readmission. Am J Hosp Palliat Care. 2020;1049909120959641. doi:10.1177/ 1049909120959641

70. Wilson MG, Lee TC, Hass A, Tannenbaum C, McDonald EG. EMPOWERing hospitalized older adults to deprescribe sedative hypnotics: a pilot study. J Am Geriatr Soc. 2018;66(6):1186-1189. doi:10.1111/jgs. 15300

71. Cao T, Johnson A, Coogle J, et al. Incidence and characteristics associated with hospital readmission after discharge to home hospice. J Palliat Med. 2020;23(2):233-239. doi:10.1089/ jpm.2019.0246

72. Garfinkel D, Ilin N, Waller A, Torkan-Zilberstein A, Zilberstein N, Gueta I. Inappropriate medication use and polypharmacy in end-stage cancer patients: isn't it the family doctor's role to de-prescribe much earlier? Int J Clin Pract. 2018;72(4):e13061. doi:10.1111/ijcp.13061

73. Huisman BAA, Geijteman ECT, Dees MK, et al. Role of nurses in medication management at the end of life: a qualitative interview study. BMC Palliat Care. 2020;19(1):68. doi:10.1186/s12904-02000574-5

74. Suchanek D. The rise and role of specialty pharmacy. Biotechnol Healthc. 2005;2(5):31-35.

75. Shreman J, Davis L, Daniels K. Addressing the polypharmacy conundrum. US Pharm. 2017;42(6):14-20.

76. Cooper JA, Cadogan CA, Patterson SM, et al. Interventions to improve the appropriate use of polypharmacy for older people: a cochrane systematic review. BMJ Open. 2015;5(12):e009235. doi:10.1136/bmjopen-2015-009235

77. Schwartz RN, Eng KJ, Frieze DA, et al. NCCN task force report: specialty pharmacy. J Natl Compr Canc Netw. 2010;8(Suppl 4):S1S12. doi:10.6004/jnccn.2010.0127

78. Costa E, Giardini A, Savin M, et al. Interventional tools to improve medication adherence: review of literature. Patient Prefer Adherence. 2015;9:1303-1314. doi:10.2147/PPA.S87551

79. Tschida S, Aslam S, Las L, et al. Outcomes of a specialty pharmacy program for oral oncology medications. Am J Pharm Benefits. 2012;4 (4):165-174. 


\section{Publish your work in this journal}

Drug, Healthcare and Patient Safety is an international, peer-reviewed open-access journal exploring patient safety issues in the healthcare continuum from diagnostic and screening interventions through to treatment, drug therapy and surgery. The journal is characterized by the rapid reporting of reviews, original research, clinical, epidemiological and post-marketing surveillance studies, risk management, health literacy and educational programs across all areas of healthcare delivery. The manuscript management system is completely online and includes a very quick and fair peer-review system. Visit http://www.dovepress.com/testimonials.php to read real quotes from published authors. 